\title{
PENERAPAN MUDHARABAH PADA BMT SEBAGAI SOLUSI EKONOMI UMAT
}

\author{
Muhammad Ali Akbar* \\ IAIN Salatiga
}

\begin{abstract}
This study discusses the application of mudharabah in BMT Syariah. The purpose of this study is to analyze the application of mudharabah in BMT Syariah. This research is the rationale for starting to build mudharabah products that can be an economic solution for the people. This study uses a descriptive exploratory qualitative approach and library research, which refers to the primary materials of the two components that are the subject of discussion, namely the study of mudharabah and Sharia BMT. Coupled with other books related to the problems studied. While the writing method used is descriptive analytic, namely by collecting actual information in detail and thoroughly from the data obtained, to be further described in accordance with the problem being studied, then analyzed directly. The result of the research is that the mudharabah product applied in BMT can be a solution to achieve a good and prosperous economy for the people. Especially in the midst of a situation when other financial institutions seem to be a difficult space for people to become economic partners.
\end{abstract}

Keywords: mudharabah, ekonomi syariah, BMT.

Paper type: Research paper

*Corresponding author: emaliakbar06@gmail.com

Received: October 30, 2021; Accepted: November 13, 2021; Available online: December, 06, 2021

Cite this document:

Akbar, M. A. (2021). Penerapan Mudharabah pada BMT sebagai Solusi Ekonomi Umat. Jurnal Masharif Al-Syariah: Jurnal Ekonomi dan Perbankan Syariah, 6(3), 876-885. doi:http://dx.doi.org/10.30651/jms.v6i3.10590

Copyright (C) 2021, Jurnal Masharif Al-Syariah: Jurnal Ekonomi dan Perbankan Syariah http://journal.um-surabaya.ac.id/index.php/Mas/index

This article is licensed under a Creative Commons Attribution-NonCommercial 4.0 International License. 


\begin{abstract}
Abstrak
Penelitian ini membahas tentang penerapan mudharabah pada BMT Syariah. Tujuan penelitian ini adalah mengalisis penerapan mudharabah pada BMT Syariah. Penelitian ini menjadi dasar pemikiran untuk mengawali membangun produk mudharabah yang dapat menjadi solusi ekonomi umat. Penelitian ini menggunakan metode pendekatan kualitatif deskriptif eksploratif dan study kepustakaan (library research), yakni mengacu kepada bahan-bahan primer dari dua komponin yang menjadi pokok pembahasan, yaitu studi tentang mudharabah dan BMT Syariah. Ditambah pula dengan buku-buku lain yang berkaitan dengan permasalahan yang diteliti. Sedangkan metode penulisan yang digunakan adalah deskriptif analitik, yaitu dengan mengumpulkan informasi aktual secara terperinci dan menyeluruh dari data yang diperoleh, untuk selanjutnya dideskripsikan sesuai dengan masalah yang sedang diteliti, kemudian dianalisis secara langsung. Hasil penelitian adalah bahwa seharusnya produk mudharabah yang diterapkan di BMT bisa menjadi solusi untuk mencapai ekonomi umat yang baik dan sejahtera. Terlebih di tengah-tengah keadaan saat lembaga keuangan lain seolah menjadi ruang yang sulit bagi umat untuk dijadikan patner ekonomi.
\end{abstract}

Kata kunci: Mudharabah, ekonomi syariah, BMT

\title{
PENDAHULUAN
}

Pada Desember 1973, mentri keuangan dari negara-negara islam dunia yang tergabung dalam Organisasi Kerja sama Islam (OKI) melaksanakan konfrensi di kota Jedah. Konfrensi tersebut menghasilkan beberapa keputusan penting, salah satunya adalah deklarasi berdirinya Islamic Development Bank (IDB). Dua tahun kemudian, tepatnya pada 20 Oktober 1975, sebagai tindak lanjut keseriusan konfrensi tersebut, dilaksanakan pelantikan dewan gubernur dan pembukaan secara formal IDB (Farida, 2010).

Berdirinya IDB pada saat itu mengawali angin segar industry ekonomi syarian di dunia, banyak negara-negara yang tergabung dalam OKI mulai mendirikan Lembaga yang mengurusi industry keuangan Syariah di negaranya. Di Indonesia industri keuangan Syariah mulai muncul pada tahun 1991 ditandai dengan berdirinya bank muamalat Indonesia (BMI) yang mulai beroperasi satu tahun kemudian. 
Seiring berjalannya waktu, industry keuangan berbasis asas keislaman ini semakin berkembang. Jika pada tahun 1991 bank syarian Indonesia pertama berdiri, kemajuan berikutnya terjadi pada tahun 1994 ditandai dengan berdirinya perusahaan asuransi Syariah pertama, yaitu Syarikat Takaful Indonesia. Perusahaan yang saat ini lebih dikenal dengan nama Takaful Keluarga ini didirikan oleh Ikatan Cendikiawan Muslim Indonesia (ICMI) melalui Yayasan Abdi Bangsa, Bank Muamalat Indonesia Tbk, PT Asuransi Jiwa Tugu Mandiri, Departemen Keuangan Republik Indonesial, para pengusaha Muslim Indonesia, dengan bantuan teknis dari Syarikat Takaful Malaysia Bhd. (STMB)

Pada tahun 1984, untuk pertama kalinya Baitul Maal wat Tamwil (BMT) mewarnai industry keuangan Syariah di Indonesia. BMT ini bermula dari sekelompok mahasiswa Institut Teknologi Bandung (ITB) di Masjid Salman yang mencoba menggerakkan Lembaga pembiayaan berbasis Syariah bagi usaha kecil menengah. Kemudian pada 1992 BMT semakin aktif dengan dukungan Ikatan Cendikiawan Muslim Indonesia (ICMI). Ketika itu, fokus BMT banyak pada kegiatan penghimpunan dan penyaluran dana zakat dari pegawai perusahaan atau instansi pemerintah. Sebagai sebuah organisasi yang didukung penuh ICMI, kemudian secara operasional ditindaklanjuti oleh Pusat Inkubasi Bisnis Usaha Kecil (PINBUK). PINBUK lalu menjadikan BMT ini lembaga pelatihan, secara tidak langsung pada saat itu telah dimulai awal dari lahirnya ribuan BMT di Indonesia.

Beberapa kajian pustaka yang bisa menjadi rujukan dalam penelitian ini salah satunya adalah jurnal yang ditulis oleh Prof. Dr. Bambang Waluyo, S.H., M.H. yang dimuat pada Jurnal Ekonomi dan Bisnis Islam (JEBIS) Vol. 2, No. 2, Juli-Desember 2016 dengan judul "IMPLEMENTASI PEMBIAYAAN MUDHARABAH PADA BANK SYARIAH UNTUK MEREALISASIKAN TUJUAN EKONOMI ISLAM".

\section{METODE PENELITIAN}

Penelitian ini merupakan penelitian kepustakaan (library research), yaitu penelitian bahan-bahan yang bersumber dari berbagaimacam 
literature perpustakaan. Adapun teknik pengumpulan data dilakukan dengan studi kepustakaan, yakni berperan aktif mempelajari buku-buku yang berkaitan dengan pancasila dan ekonomi Islam.

Beberapa tahapan dalam mengaji data-data tersebut adalah (Moleong, 2018):

\section{Pengecekan Keabsahan Data}

Pengecekan keabsahan data menerapkan empat kriteria, yaitu kepercayaan (cridebility), keteralihan (tranferability), kebergantungan (dependability), dan kepastian (konfirmability).

2. Metode Penulisan

Dalam membahas dan menganalisa digunakan metode deskriptif analitik, yaitu mengumpulkan informasi aktual secara terperinci dari data sebagai deskipsi masalah untuk dianalisis secara langsung, sehingga dapat disusun sebagaimana yang diperlukan dalam penelitian ini.

3. Metode Analisa Data

Dengan menggunakan content analisis yang menganalisis pendapat seseorang kemudian ditambah pendapat lain lalu diambil kesimpulan.

\section{HASIL DAN PEMBAHASAN}

\section{Konsep mudharabah dan keunggulannya}

Mudharabah dapat dimaknai sebagai akar kerja sama antara dua pihak, yaitu pengelola usaha yang dikenal sebagai mudharibin dan pihak pemilik modal yang dikenal dengan istilah shahibul mall (IImi, 2002).

Konsep pelaksanaan mudharabah harus merpondasi pada kepercayaan dan rasa keadilan. Hal ini dicerminkan dengan pelaksanaannya, yaitu apabila dalam kerja sama terjadi kerugian yang disebabkan oleh konsekuensi bisnis (bukan penyelewengan atau keluar dari kesepakatan) maka pihak shahibul mall akan ikut serta menanggung kerugian, berbagi dengan mudharib yang akan menanggung kerugian managerial skill dan waktu serta nisbah keuntungan bagi hasil yang akan diperolehnya. 
Kepercayaan sangan penting dalam akad mudharabah karena shahibul mall tidak boleh ikut campur di dalam manajemen proyek yang dibiayainya, kecuali sebatas memberikan saran-saran dan melakukan pengawasan pada pengelola dana (Wasilah, 2014). Oleh karena itu, mudharib sebagai pihak yang diberi amanah dan dipercaya untuk mengelola usaha hendaknya harus meneladani sifat Rasulullah saw. yaitu shiddiq, tabligh, amanah dan fathonah. Tanpa dilandasi hal tersebut, tidak ada keadilan antara pemilik dana dan pengelola dana.

M. Syaf'i Antonio, dalam bukunya "Bank Syariah Dari Teori dan Praktek", menjelaskan bahwa akad yang sesuai dengan prinsip investasi adalah mudharabah. Tujuan dari mudharabah adalah kerja sama antara shahibul maal dan mudharib.

Dari pendapat M. Syafi'l Antonio tersebut, kita memahami bahwa salah satu keunggulan mudharabah sebagai pembiayaan dalam ekonomi syariah sangat berperan penting bagi investasi. Hal ini dapat menjadi awal dari angin segar bagi umat untuk memulai dan mengembangkan usaha dengan memanfaatkan mudharabah sebaik-baiknya.

Selain memiliki pengaplikasian yang mudah dan aman, mudharabah juga sudah jelas sejalan dengan tujuan mulia ekonomi Syariah itu sendiri, yaitu mencapai kebahagiaan dan kesejahteraan semua umat berdasarkan ajaran Allah SWT yang disampaikan melalui Nabi Muhammad SAW.

\section{Penerapan mudharabah sebagai produk BMT}

Baitul Maal wa Tamwil (BMT) adalah lembaga keuangan mikro yang dioperasikan dengan prinsip bagi hasil. Saat ini perkembangan BMT di Indonesia sudah meningkat pesat dari tahun ke tahun, di beberapa daerah bahkan telah memiliki basis BMT yang sangat besar, seperti BMT Sidogiri di Jawa Timur yang memiliki total aset hingga 2,6 triliun.

BMT merupakan lembaga keungan miko yang terdiri atas dua kegiatan sekaligus, yaitu Baitul Maal dan Baitul Tamwil. Kegiatan Baitul Maal dalam BMT berfungsi sebagai lembaga keuangan yang kegiatannya mengelola dana bersifat nirlaba (sosial). Sumber dana diperoleh dari zakat, infaq dan sedekah, atau sumber lain yang halal. Dana tersebut 
kemudian disalurkan kepada mustahik, yang berhak, atau untuk kebaikan. Sedangkan kegiatan Baitul Tamwil adalah menjadi lembaga keuangan yang berfungsi sebagai penghimpun dan penyalurkan dana masyarakat dan bersifat profit-oriented.

BMT memiliki tujuan untuk meningkatkan kualitas usaha ekonomi untuk kesejahteraan anggota pada khususnya dan umat pada umumnya. Dari tujuan tersebut dapat dipahami bahwa BMT berorientasi pada upaya peningkatan kesejahteraan anggota dan umat. Anggota harus diberdayakan supaya dapat mandiri, sehingga dengan menjadi anggota BMT, umat dapat meningkatkan taraf hidup melalui peningkatan usahanya sendiri.

Untuk menjalankan misinya dalam memperbaiki ekonomi umat sesuai dengan ajaran islam, maka BMT menerapkan sistematika pengelolaan keuangan berdasarkan hukum-hukum islam, mulai dari pelayanan, produk hingga tujuan besarnya secara umum.

Ibrahim Hosen menyatakan bahwa fungsi hukum Islam tidak hanya untuk ibadah amar maruf nahi munkar, melainkan juga sebagai zawahir (sarana pemaksa yang melindungi warga masyarakat dari segala bentuk yang membahayakan), dan tanzim wa islah al-ummah yaitu mengatur sebaik mungkin dan memperlancar proses interaksi sosial sehingga terwujud masyarakat yang harmonis, aman dan sejahtera (baldatun tayyibatun wa rabbun ghafur) (Ahmad, 1966).

Dari penerapan tersebut, dikenalah beberapa produk pembiayaan basis islam yang memiliki system dan manfaat masing-masing, antara lain wadiah, mudharabah, musyarakah, murabahah, salam, istisna', ijarah, ijarah muntahiyah bit tamlik dan qardh (OJK).

Mudharabah sebagai salah satu produk tersebut menjadi salah satu dari produk yang banyak dipilih anggota dan umat yang menggunakan manfaat BMT. Hal ini dikarenakan mekanismenya yang mudah dan sederhana, sehingga dengan cepat dapat dipahami dan dipraktekkan.

Dalam sistem keuangan BMT, modal bagi hasil berlaku untuk akad peyertaan usaha atau kerjasama usaha (partnership, project, financing 
participation). Dalam bagi hasil ini ada dua pihak yang saling berhubungan, pertama financier, yaitu yang meyediakan dana yang dibutuhkan untuk menjalankan usaha dengan maksud untuk menghasilkan laba (profit). Pihak kedua sepenuhnnya menjalankan peran usaha.

Dalam pelaksanaan program pembiayaan simpanan berjangka di BMT, akad yang digunakan adalah mudharabah, yaitu aliran dana berasal dari satu anggota yang mempercayainya kepada BMT, sehingga BMT dapat berperan sebagai pengelola dana tersebut dan menyalurkan lagi kepada anggota lainnya atau usaha mikro kecil menengah yang membutuhkan sebagai modal untuk membuka dan membangun usaha.

Pada dasarnya pengaplikasian mudharabah ini didasarkan pada kerjasama mu'awadlah yakni saling mempertukarkan modalnya masingmasing, baik harta dengan harta atau harta dengan tenaga, serta terhindar dari riba dan hal-hal yang samar atau ghoror.

\section{Mudharabah sebagai solusi ekonomi umat}

Dalam Pasal 33 UUD 1945, sangat jelas mencantumkan tujuan akhir kemakmuran rakyat secara maksimal. Perekonomian harus disusun berdasar demokrasi ekonomi, di mana kemakmuran masyarakat lebih diutamakan dari pada kemakmuran individu (Mubyarto, 1987).

Sesuai dengan isi Pasal 33 UUD 1945 tersebut, maka peran BMT sebagai salah satu pilar yang menjadi penopang para pelaku usaha mikro kecil menengah di Indonesia sangat tepat dan penting sekali. BMT yang menerapkan system kerja sama yang mengandalkan kepercayaan, kejujuran serta rasa keadilan menjadi lembaga keuangan yang pada akhirnya merupakan pilihan paling masuk akal bagi umat.

Terlebih Ketika dihadapkan dengan situasi ekonomi saat ini, lembaga keuangan yang lebih professional seperti bank, baik bank Syariah atau pun bank konvensional, tidak menjadi pilihan utama umat dalam menghimpun dana, disebabkan oleh sitem yang dianggap rumit dan beban perjanjian yang sangat beresiko. 
Menurut Yusuf Qardhawi Ekonomi Islam mempunyai empat karakteristik (Qardhawi, 1997):

a. Rabbaniyyah (Ketuhanan)

Karakteristik pertama dalam ekonomi islam adalah rabbaniyyah. Maksudnya adalah setiap perilaku ekonomi haruslah berdasarkan pada prinsip ketaatan yang mendahulukan hukum Allah SWT. yaitu, melaksanakan segala perintahnya dan menjauhi segala larangannya.

b. Insaniyyah (Kemanusiaan)

Unsur kemanusian tak luput menjadi salah satu karakteristik dari ekonomi islam. Sebagai peran dan tujuan dari kegiatan ekonomi itu sendiri tentu peran manusia menjadi salah satu yang harus diperhatikan dalam melaksanakan kegiatan ekonomi. Memahami bahwa tujuan akhir dari kegiatan ekonomi adalah untuk mencapai kehidupan yang baik di dunia dan akhirat.

c. Akhlaqiyyah (Etika)

Etika merupakan salah satu hal yang tidak bisa dipisahkan dalam aktifitas ekonomi, begitu juga dalam semua aktifitas yang berkaitan dengan sosial masyarakat.

d. Wasathiyyah (Keseimbangan)

Inilah salah satu tujuan penting yang harus dicapai dari perilaku ekonomi, yaitu keseimbangan dalam kehidupan bermasyarakat.

Dari persip-perinsip tersebut, pada akhirnya BMT menjadi barisan paling depan sebagai pendongkrak kemajuan ekonomi umat. Sehingga dengan sangat tepat, maka mudharabah sebagai pembiyaaan pada BMT yang sangat mudah dan sederhana, dapat dimanfaatkan sebaik mungkin oleh umat sebagai solusi untuk membangung usaha, mencapai tujuan bahagia dan sejahtera, serta sesuai dengan prinsip Islam yang mendasar.

\section{KESIMPULAN DAN SARAN}

Berdasarkan pembahasan tentang konsep mudharabah, peran BMT serta tujuan akhir dari ekonomi, maka dapat disimpulkan bahwa mudharabah sebagai salah satu produk BMT yang sangat sederhana dan 
mudah dipraktekkan oleh seluruh umat, sangat tepat menjadi solusi ekonomi. Terlebih dalam kondisi saat banyak lembaga keuangan (Syariah dan konvensional) yang semakin dianggap rumit dan menyulitkan.

Berdasarkan kesimpulan yang telah dipaparkan, terdapat beberapa saran sebagai berikut:

1. Diharapkan dengan hadirnya jurnal ini, seluruh insan akademis dapat lebih memahami penerapan mudharabah, fungsi BMT dan tujuan ekonomi syariah sesungguhnya, sehingga kemudian dapat memilih rujukan yang baik dalam menjalankan sistem perekonomian Syariah yang membawa dampak positif terhadap kehidupan sosial bermasyarakat, berbangsa dan bernegara.

2. Bagi para cendikiawan, hendaknya dapat meneliti lebih lanjut argumentasi ekonomi syaraiah, terlebih mengenai penerapan produk agar dapat dipahami sesuai dengan prinsip islam itu sendiri.

3. Diharapkan kepada pihak pemerintah agar melaksanakan strategi pembangunan ekonomi umat yang sesuai dengan cita-cita dan kebutuhan dengan memanfaatkan peran BMT.

\section{DAFTAR PUSTAKA}

\section{Buku}

Moleong, Lexi J. (2018). Metodologi penelitian kualitatif. Bandung: PT Remaja Rosdakarya.

Suggono, Bambang. (2006). Metodologi Penelitian Hukum. Jakarta: Raja Grafindo Persada.

Ilmi, Makhalul. (2002). Teori dan Praktek Lembaga Mikro Keuangan

Syariah. Yogyakarta: UII Press.

Wasilah, Sri Nurhayati. (2014). Akuntansi Syari'ah di Indonesia. Jakarta:

Salemba Empat.

Ahmad, Amrullah, dkk. (1966) Dimensi Hukum Islam dalam Sistem Hukum Nasional. Jakarta: Gema Insani Press. 
Mubyarto. 1987. Ekonomi Pancasila, 126 Gagasan dan Kemungkinan. Jakarta: LP3ES

Qardhawi, Yusuf. ter. Didin Hafidhuddin. 1997. Peran Nilai dan Moral Dalam Perekonomian Islam. Jakarta: Robbani Press

\section{Artikel Jurnal}

Farida, Ulfa Jamilatul. (2010). Prospek Islamic Development Bank (IDB) Sebagai Representasi Kebangkitan Sistem Ekonomi Islam di Tengah Konstelasi Ekonomi Internasional. Jurnal La_Riba, Volume IV No. 1.

Mashuri. Peran Baitul Maal Wa Tamwil (BMT) Dalam Upaya

Pemberdayaan Ekonomi Masyarakat. https://media.neliti.com/.

Internet

Sejarah Asuransi Syariah Pertama Di Indonesia. Diakses pada 12 September 2021 jam 00.19, dari https://www.takafulumum.co.id/

100 Koperasi Besar Indonesia Bukukan Aset Rp66,6 Triliun. Diakses pada 12 September 2021 jam 01.19, dari https://rri.co.id/

Akad-akad Dalam Transaksi Perbankan Syariah. Diakses pada 12 September 2021 jam 01.30, dari https://www.ojk.go.id/ 